\title{
Plurality and crosslinguistic variation: an experimental investigation of the Turkish plural
}

\author{
Agata Renans ${ }^{1} \cdot$ Yağmur Sağ $^{2} \cdot$ F. Nihan Ketrez ${ }^{3} \cdot$ Lyn Tieu $^{4} \cdot$ George Tsoulas $^{5}$. \\ Raffaella Folli ${ }^{6} \cdot$ Hana de Vries $^{5} \cdot$ Jacopo Romoli $^{7}$
}

\begin{abstract}
In English and many other languages, the interpretation of the plural is associated with an 'exclusive' reading in positive sentences and an 'inclusive' reading in negative ones. For example, the plural noun tulips in a sentence such as Chicken planted tulips suggests that Chicken planted more than one tulip (i.e., a reading which 'excludes' atomic individual tulips). At the same time, however, the corresponding negative sentence Chicken didn't plant tulips doesn't merely convey that he didn't plant more than one tulip, but rather that he didn't plant any tulip (i.e.,
\end{abstract}

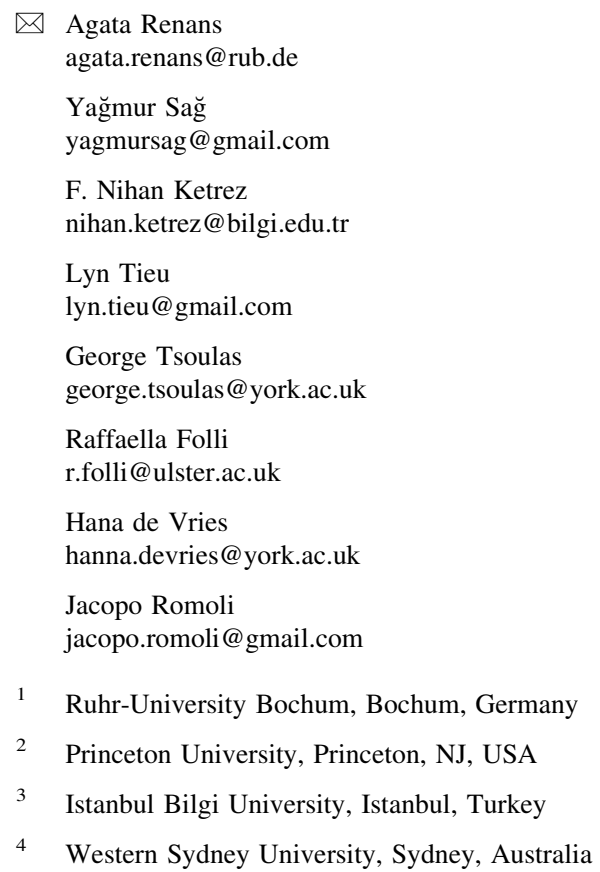


'including' atomic individual tulips). Different approaches to the meaning contribution of the English plural vary in how they account for this alternation across the polarities, but converge on assuming that (at least one of) the denotation(s) of the plural should include atomic individuals. Turkish, on the other hand, is cited as one of the few known languages in which the plural only receives an exclusive interpretation (e.g., Bale et al. Cross-linguistic representations of numerals and number marking. in: Li, Lutz (eds) Semantics and linguistic theory (SALT) 20, CLC Publications, Ithaca, pp 582-598, 2010). More recent proposals have, however, argued that the Turkish plural should in fact be analysed more like the English plural (e.g., Sağ, The semantics of number marking: reference to kinds, counting, and optional classifiers, PhD dissertation, Rutgers University, 2019). We report two experiments investigating Turkish-speaking adults' and preschool-aged children's interpretation of positive and negative sentences containing plural nouns. The results provide clear evidence for inclusive interpretations of the plural in Turkish, supporting accounts that treat the Turkish and English plurals alike. We briefly discuss how an inclusive meaning of the Turkish plural can be integrated within a theory of the Turkish number system which captures some idiosyncratic properties of the singular and the agreement between number and number numerals.

Keywords Plural · Experimental studies · Implicatures · Turkish

\section{Introduction}

As is well known, the plural in English (and many other languages) is associated with more than one possible interpretation. For example, a plural noun like tulips in a sentence such as (1) suggests that Chicken planted multiple tulips (i.e., a reading which 'excludes' atomic individual tulips). At the same time, however, when the same noun appears in a negative sentence such as (2), it doesn't merely convey that Chicken didn't plant multiple tulips, but rather that he didn't plant any tulip (i.e., 'including' atomic individual tulips; Krifka 1989; Sauerland et al. 2005; among others). The first reading is generally referred to as the exclusive reading, and the latter the inclusive one.

(1) Chicken planted tulips.

$\leadsto$ Chicken planted multiple tulips EXCLUSIVE READING

(2) Chicken didn't plant tulips.

$\leadsto$ Chicken didn't plant any tulip INCLUSIVE READING

The main approaches to the semantics of the English plural differ in how they account for this alternation across the polarities, but they all converge on the

5 University of York, York, UK

6 Ulster University, Newtownabbey, UK

7 University of Bergen, Bergen, Norway 
assumption that (at least one of) the denotation(s) of the plural should include atomic individuals (Sauerland et al. 2005; Spector 2007; Mayr 2015; Ivlieva 2013; Zweig 2009; Martí 2020a; Grimm 2013; Farkas and de Swart 2010; Križ 2015, 2017).

By contrast, Turkish, together with a few other languages, such as Western Armenian and Korean, is often cited as one of the few known languages in which the plural only receives an exclusive interpretation (Bale et al. 2010; Bale and Khanjian 2014; Görgülü 2012), suggesting that the denotation of the plural can never include atomic individuals. Recent accounts, however, have argued against this claim and have proposed instead that the plural in Turkish be analysed more like the plural in English, giving rise to the same alternation of readings (Kan 2010; Sağ 2018, 2019). It is therefore controversial whether the plural in Turkish should be assigned an exclusive denotation or whether an inclusive denotation is also possible.

In this paper, we report two experiments designed to investigate this question. We tested Turkish-speaking adults' and preschool-aged children's interpretation of plurals in positive and negative sentences. The results provide clear evidence for an inclusive interpretation of the plural in Turkish, supporting the approach which argues that it should be analysed like the plural in English in this respect (Kan 2010; Sağ 2018, 2019). ${ }^{1}$ We discuss the three main existing accounts of the inclusiveexclusive alternation and how they fare with respect to our results in Turkish. We also briefly discuss, with reference to recent proposals by $\operatorname{Sag}(2018,2019)$ and Martí (2020a), how an inclusive meaning of the Turkish plural can be integrated within a theory of the Turkish number system in general which covers well-known idiosyncratic properties of the singular and agreement between number and numerals.

Whether Turkish is a language with an exclusive-only plural or not is an important question not only for our understanding of the properties of the Turkish plural, but also as a means to gain a better understanding of the different meanings that the plural can obtain across languages, thereby constraining crosslinguistically adequate theories of the semantics of number marking.

The rest of the paper is organised as follows. In Sect. 2, we discuss the exclusive versus inclusive interpretations of the plural in English and the three main existing theoretical proposals. We then move to the case of Turkish, outlining the differences between English and Turkish and their accounts in the literature. The predictions of the different approaches are discussed in detail in Sect. 3. Subsequently, we report on our experimental study in Sect. 4 and its follow-up in Sect. 5. In Sect. 5.3 we discuss the results. We briefly outline in Sect. 6 how an inclusive interpretation of the plural can be integrated within a general theory of the number-marking system in Turkish. Section 7 concludes the paper.

\footnotetext{
${ }^{1}$ For a similar investigation and conclusion for the plural in Buryat, see Bylinina and Podobryaev (2020).
} 


\section{Background}

\subsection{The plural in English}

\subsubsection{The empirical picture}

As already discussed above, a sentence like (3) in English suggests that Chicken planted multiple tulips, giving rise to the so-called exclusive interpretation of the plural; this is not an interpretation that is associated with the corresponding singular sentence in (4).

(3) Chicken planted tulips.

$\leadsto$ Chicken planted more than one tulip

EXCLUSIVE READING

(4) Chicken planted a tulip.

y $\rightarrow$ Chicken planted more than one tulip

However, this exclusive reading generally disappears when the plural noun appears in a downward-entailing context, as in (5). That is, (5) typically does not merely convey that Chicken didn't plant multiple tulips, but rather that he didn't plant any tulip at all.

(5) Chicken didn't plant tulips.

$\leadsto$ Chicken didn't plant any tulip

INCLUSIVE READING

The same holds for other downward-entailing contexts, such as the restrictor of universal quantifiers and questions, as shown below: ${ }^{2}$

(6) Every chicken who planted tulips will be rewarded.

$\leadsto$ Every chicken who planted one or more tulips will be rewarded

(7) Did Chicken plant tulips?

INCLUSIVE READING

$\leadsto$ Did Chicken plant one or more tulips?

INCLUSIVE READING

Sentences like (5) can also obtain the weaker exclusive reading that Chicken didn't plant multiple tulips, but this has to be forced by the context-for example, by a continuation that is incompatible with the inclusive reading, as illustrated in (8) (which is typically pronounced with stress on the plural noun).

(8) Chicken didn't plant TULIPS ...he planted only one!

\footnotetext{
${ }^{2}$ It is controversial whether questions are downward-entailing contexts. What is relevant for us, however, is that they pattern with other downward-entailing contexts with respect to the interpretation of plural nouns.
} 
A theory of the plural in English therefore has to account for the alternation between the exclusive and inclusive readings, while also allowing for the exclusive interpretation to re-emerge as a dispreferred option in cases like (8).

There are three main accounts of the English plural in the literature: the implicature approach (e.g., Sauerland et al. 2005; Spector 2007; Zweig 2009; Ivlieva 2013; Mayr 2015), the ambiguity approach (Farkas and de Swart 2010; Grimm 2013; Martí 2020a), and the homogeneity approach (Križ 2015, 2017). While different, all of these approaches have in common the assumption that (at least one of) the denotation(s) of the plural should include atomic individuals. That is, one denotation is inclusive. For this reason we will call this approach the inclusive approach. ${ }^{3}$ For instance, in a context in which the relevant tulips are $a, b$, and $c$, the literal meaning of the plural noun tulips would include the atomic individual tulips and the sets thereof, as in (9) (cf. Schwarzschild 1996).

$$
\llbracket \text { tulips } \rrbracket=\{a, b, c,\{a, b\},\{a, c\},\{b, c\},\{a, b, c\}\} \quad \text { INCLUSIVE MEANING }
$$

The meaning in (9), combined with the rest of the sentence in (3), thus gives rise to an inclusive reading, which can be paraphrased as in (10).

(10) Chicken planted one or more tulips.

As is easy to see, positing the inclusive meaning of the plural in (9) makes the right prediction for cases like (5), which can simply be analysed as the negation of (10), as in (11), conveying that Chicken didn't plant any tulip.

(11) Chicken didn't plant one or more tulips.

What remains to be explained, of course, is how the exclusive meaning arises in cases like (3). The three main accounts differ in how they derive this interpretation. We next briefly discuss each of these in turn.

\subsubsection{Existing Theories}

The three inclusive accounts of the English plural, i.e., the ambiguity account, the implicature account, and the homogeneity account, share the following properties: (i) they assume that the plural can have an inclusive meaning as in (9), (ii) they predict the alternation between inclusive and exclusive readings discussed above, albeit in different ways, and (iii) they allow for the exclusive reading to emerge as a marked option for cases like (8).

The ambiguity account The ambiguity account, defended mainly in Farkas and de Swart (2010), Martí (2020a), and Grimm (2013), posits that the plural is ambiguous between the inclusive meaning in (9) and the exclusive one in (12). When (12) is combined with the rest of the sentence in (3), the reading it gives rise to is the exclusive one in (13).

\footnotetext{
3 This denotation is sometimes also referred to as number-neutral or semantically unmarked. We will use the more neutral inclusive and exclusive terminology throughout the paper.
} 
(12) $\llbracket$ tulips $\rrbracket=\{\{a, b\},\{a, c\},\{b, c\},\{a, b, c\}\}$

EXCLUSIVE MEANING

(13) Chicken planted more than one tulip.

In addition, this approach assumes that the choice between the exclusive and the inclusive meaning of the plural is regulated by a pragmatic principle favouring the strongest possible interpretation whenever possible in the context, as formulated in (14).

\section{(14) The Strongest Meaning Hypothesis for plurals:}

For a sentence involving a plural nominal, prefer that interpretation of the plural which leads to the stronger overall interpretation for the sentence as a whole, unless this interpretation conflicts with the context of utterance.

This predicts that in a positive context like (3), the exclusive reading in (13) will be favoured, as it is stronger than the corresponding inclusive one in (10). Under negation, on the other hand, entailment relations reverse, so it is the inclusive reading in (11) which will be favoured over the corresponding exclusive one in (15).

\section{(15) Chicken didn't plant more than one tulip.}

Finally, the principle in (14) is formulated in such a way as to allow for a weak interpretation if the stronger one is in conflict in some way with the context of utterance. This predicts that in a case like (8) the weak exclusive interpretation is possible, because the stronger inclusive one would contradict the continuation of the sentence.

In sum, the ambiguity approach predicts the alternation between exclusive and inclusive readings by positing an ambiguous meaning for the plural and a pragmatic principle regulating the choice between the two possible meanings based on logical strength.

The implicature account A different take on the inclusive-exclusive alternation of the English plural is the implicature account developed in Sauerland (2003), Sauerland et al. (2005), Spector (2007), Zweig (2009), Ivlieva (2013), and Mayr (2015), among others. There are three main ingredients to this account: an inclusive literal meaning for plural nouns, an assumption about competition between the singular and the plural, and a theory of implicatures. The first ingredient is common to all accounts within the inclusive approach. Given the assumption that the literal meaning of plural nouns is inclusive, (16a) can be paraphrased as in (16b):

(16) a. Chicken planted tulips.

b. $\approx$ Chicken planted one or more tulips

LITERAL MEANING

As for the second ingredient, an assumption regarding the competition between the singular and the plural is that the plural in (16a), whose literal meaning is the 
inclusive one in (16b), competes with an alternative sentence which we can paraphrase as in $(17):^{4}$

\section{(17) Chicken planted exactly one tulip.}

The third ingredient is a theory of implicatures. The standard approach treats scalar implicatures as arising from the hearer's reasoning about what the speaker actually said as compared to what she could have said instead, assuming she was being cooperative for the purposes of the conversation (see Grice 1975 and much subsequent work). Without going into details: in the case of (16a) the hearer assumes that the speaker will convey the strongest relevant piece of information she believes to be true. Therefore, upon hearing (16) the hearer will assume that the stronger alternative in (17) must be false. But then, if (16) is true and (17) is false, this leads to the exclusive reading that Chicken planted more than one tulip.

(18) Chicken planted tulips (=Chicken planted one or more tulips), and it is not true that Chicken planted exactly one tulip.

$=$ Chicken planted more than one tulip

EXCLUSIVE READING

As for the negative case, negation reverses the entailment relation and therefore (20) is now weaker than (19). Thus, upon hearing (19) the listener will not draw any inference from it.

(19) Chicken didn't plant tulips.

(20) Chicken didn't plant exactly one tulip.

As noted, sentences like (19) can sometimes obtain an additional marked reading as in (8). For the implicature approach, this would be a case in which the implicature is computed locally, under negation. That is, the implicature is first computed, giving rise to the meaning that Chicken planted more than one tulip; this meaning is then negated, giving rise to the meaning that Chicken didn't plant more than one tulip (he planted only one).

The homogeneity account Križ $(2015,2017)$ proposes an alternative approach to the multiplicity inference in terms of homogeneity. The main idea is that most predicates are undefined under certain conditions when they apply to pluralities. As Križ (2017) shows, when a (homogeneous) predicate appears in an episodic sentence such as (21), it gives rise to the following trivalent truth conditions: it is true when both (22a) and (22b) are true, false when both are false, and undefined otherwise. This gives us the intuitively correct reading of the sentence in (21), namely that it's true if and only if Chicken planted more than one tulip.

(21) Chicken planted tulips.

(22) a. Chicken planted one or more tulips.

b. Chicken planted multiple tulips.

\footnotetext{
4 The different implicature approaches to the exclusive reading vary in how they derive the alternative in (17); see Tieu and Romoli (2019) for an overview.
} 
When (21) is negated, as in (23), the undefinedness is unaffected by negation, so that the conditions for (23) are as follows: (23) is true when both (24a) and (24b) are true, false when both are false, and undefined otherwise. These appear to be the correct conditions for (23); in particular, they capture the intuition that the sentence is true if and only if Chicken didn't plant any tulip.

(23) Chicken didn't plant tulips.

(24) a. Chicken didn't plant one or more tulips.

b. Chicken didn't plant multiple tulips.

In sum, the homogeneity approach can account for the alternation between positive and negative cases.

For the marked case in (8), Križ (2017) appeals to a pragmatic principle for dealing with undefinedness, which allows the use of a sentence even if it is undefined in the context, as long as the actual situation that makes the sentence undefined is equivalent to a situation that would make the sentence true. ${ }^{5}$ For instance, in (5), the prediction is that it can be used felicitously to the extent that we can accommodate in the context that the distinction between Chicken planting just one tulip and her planting no tulip is not relevant (i.e., it only matters whether she planted more than one tulip, not whether she planted tulips at all).

Summary The plural in English (and many other languages) gives rise to inclusive and exclusive readings in different contexts. The main theoretical accounts in the literature agree on the assumption that the plural can have an inclusive meaning, but derive the exclusive reading in different ways. In the next subsection, we turn to discuss the case of Turkish, which has been argued to work quite differently from English in this respect. In particular, Turkish has been argued to be a language in which the plural can only be interpreted exclusively.

\subsection{The plural in Turkish}

\subsubsection{The empirical picture}

Basic cases Turkish plural nouns also give rise to exclusive readings. As with its English counterpart, a sentence like (25) with a (non-case-marked) plural noun in object position conveys the meaning that Chicken planted more than one tulip. ${ }^{6} \mathrm{We}$

\footnotetext{
5 This principle is summarised in (i).

(i) An undefined sentence can be used when the situation described in the context is, for current purposes, equivalent to the situation in which the sentence is true (Križ 2017).

6 Accusative-marked nouns in object position convey a specific/definite interpretation. For this reason, we focus on unmarked bare plurals throughout the paper.
} 
have added the modifier 'with blue petals' as this improves the felicity of the sentence for most speakers. ${ }^{7}$

(25) Tavuk (mavi yaprak-11) lale-ler dik-ti.
chicken blue petal-with tulip-PL plant-PAST
'Chicken planted tulips (with blue petals).'
$\rightsquigarrow$ Chicken planted more than one tulip (with blue petals)
EXCLUSIVE READING

What is more controversial is the question of whether inclusive readings are possible in Turkish. In fact, as already mentioned, Turkish is often cited as one of the few known languages in which the plural can only be interpreted exclusively.

Recently, however, the question of whether Turkish is a language with an exclusive-only plural has become a subject of controversy. On the one hand, Bale and Khanjian (2014) and Bale et al. (2010) argue that the plural in Turkish is never interpreted inclusively. The main focus of their papers is Western Armenian, but they argue that their account extends to Turkish. As Bale and Khanjian (2014: fn: 15) propose: "The theory advanced [...] can also account for the distribution of singular and plural in Turkish, a language that has many of the same properties as Western Armenian." They provide examples (26) and (27) as evidence that the plural in Western Armenian is interpreted only exclusively both in upward- and downward-entailing contexts. That is, in (27), the plural noun receives an exclusive interpretation, despite appearing in a downward-entailing context, unlike the corresponding cases in English discussed above. ${ }^{8}$

(26) Western Armenian

Dəgha-ner vaze-ts-in.

boy-PL run-PST-3PL

'Two or more boys ran.'

(Bale and Khanjian 2014)

(27) Western Armenian

?Amen mart vor bədig-ner uner vodk-i gajne-tsav.

all person that child-PL had foot-DAT stand.up-PST

'Everyone that had two or more children stood up.'

(Bale and Khanjian 2014, p.4)

More recent work by Kan (2010) and Sağ (2018, 2019), on the other hand, has argued that the Turkish plural does give rise to the same exclusive vs. inclusive alternation as in English, as demonstrated for instance in (28) vs. (29) (from Sağ 2018).

\footnotetext{
7 In the two experiments reported below, we tested plural nouns with and without a modifier.

${ }^{8}$ Bale and Khanjian (2014) note that Armenian native speakers prefer a singular noun in (27), but if they are asked to interpret the sentence, they interpret the plural exclusively.
} 
(28)

$\begin{array}{llll}\text { Çocuk-lar } & \text { sokak-ta } & \text { top } & \text { oynu-yor. } \\ \text { child-PL } & \text { street-LOC } & \text { ball } & \text { play-PROG }\end{array}$

EXCLUSIVE

'Children are playing ball on the street.'

$\leadsto$ More than one child is playing ball on the street

(29)

$\begin{array}{llll}\text { Çocuk-lar } & \text { sokak-ta } & \text { top } & \text { oyna-m1-yor. } \\ \text { child-PL } & \text { street-LOC } & \text { ball } & \text { play-NEG-PROG }\end{array}$

INCLUSIVE

'Children aren't playing ball on the street.'

$\leadsto$ No child is playing ball on the street

In addition, the inclusive reading appears to extend beyond negation, as the examples below from Sağ (2018) show. That is, (30) intuitively would be answered in the affirmative if just one bear was encountered; (31) suggests that cheating by just one man is enough for joining; and similarly for (32). ${ }^{9}$
Orman-da
ay1-lar-la
karşılaş-t1-n1z
mi?
forest-LOC bear-PL-COM come.across-PAST-2PL QUEST
'Did you come across bears in the forest?'

$\begin{array}{ll}\text { Eğer } & \text { erkek-ler tarafindan } \\ \text { if } & \text { man-PL by } \\ \text { biz-e } & \text { katıl-abil-ir-sin } \\ \text { we-DAT } & \text { join-ABIL-AOR-2sG }\end{array}$

aldat-1l-d1-y-sa-n, sen de cheat-PASS-PAST-COP-COND-2SG you also 'If you have been cheated by men, you can join us.'

Erkek-ler tarafından aldat-1l-an herkes biz-e kat1l-abil-ir.
man-PL by cheat-PASS-REL everybody we-DAT join-ABIL-AOR
'Everyone who has been cheated by men can join us.'

In sum, contra previous claims by Bale et al. (2010), Bale and Khanjian (2014), and others, the data from Sağ (2018) show that the Turkish plural can receive a genuine inclusive denotation in addition to the exclusive one, unlike Western Armenian. ${ }^{10}$ Given the controversial nature of these claims in the literature, we

\footnotetext{
${ }^{9}$ Bale and Khanjian (2009) suggest that negation would not be a good downward-entailing context to test the interpretation of the plural. Their argument is that in Western Armenian, negation patterns differently from other downward-entailing contexts, such as the restrictor of the universal quantifier. They argue that in all of these environments bare plurals only have an exclusive reading, but in negated sentences, an inclusive reading seems to re-emerge. We tested only negation in our experiments, so we acknowledge that further experimental work is required to determine whether there really is a distinction between negation and other downward-entailing environments in Turkish. Note, however, that the above examples from Sağ (2018) of Turkish bare plurals in questions and other downward-entailing contexts suggest that the plural in Turkish does have an inclusive reading in these contexts as well.

${ }^{10}$ Though note that all Western Armenian examples we are aware of that exhibit exclusive denotations contain the predicate uni 'have'. This is one place where bare singulars have an inclusive denotation (see Sigler 1996). We suggest that the availability of the inclusive reading of bare singulars with the 'have' predicate might be the reason for the seemingly exclusive reading of bare plurals. While we think this should be tested experimentally, some initial fieldwork conducted by some of us with eight native speakers of Western Armenian suggests that once we move away from the predicate 'have', the inclusive
} 
believe a systematic experimental investigation is crucial to provide further insight on this question.

Other properties of the Turkish plural Before we sketch more systematically the two possible approaches to the Turkish plural outlined above (i.e., whether the Turkish plural is only exclusive or whether it has both an inclusive and an exclusive reading), let us first mention some other characteristic properties of the Turkish number system which set it apart from the English system, and which are important for our experimental design.

First, it has long been observed in the literature that the singular in Turkish can obtain an inclusive interpretation in certain contexts compatible with plural individuals (Bliss 2004; Bale et al. 2010; Görgülü 2012; Scontras 2014; Săg 2018, 2019; Martí 2020b). That is, while (33) in English suggests that Chicken planted just one tulip, the corresponding sentence in Turkish is compatible with Chicken planting more than one tulip. ${ }^{11}$

(33) Chicken planted a tulip.

(34) Tavuk lale dik-ti.

chicken tulip plant-PAST

'Chicken planted a tulip.'

It is important to note that this interpretation of the singular is restricted to certain contexts, but we will come back to this below.

A second property of the Turkish number system which is well known to be different from that of English is the interaction between number marking and

Footnote 10 continued

reading does arise in downward-entailing contexts. Some of the examples used are the following (see also Sağ 2019):

(i) jete gin-er-e tavazan-v-etsar, gərnas mer xump-i-n mijanal.

if woman-PL-ABL betray-PASS-2SGPAST can.2SGPRES our group-DAT-DEF join.INF

'If you are betrayed by women, you can join our group.' (one or more women)

(ii) Context: We go to the forest and see one bear there.

arts-er des-ak?

bear-PL see-2PLPAST

'Did you see bears?'

a. ayo meg had mə des-ank

yes one CL INDEF see-1PLPAST

'Yes, we saw one.'

b. \#vot (minag) meg had des-ank

no only one CL see-1PLPAST

'No, we (only) saw one.'

11 Another way to express the meaning that Chicken planted a tulip is with the use of the indefinite/numeral bir:

(i) Tavuk bir lale dik-ti.

chicken INDF tulip plant-PAST

'Chicken planted a tulip.' 
numerals: while English numerals other than "one" require plural nouns, Turkish numerals can only combine with the singular (Ionin and Matushansky 2006; Bale et al. 2010; Să̆ 2018, 2019).

(35) Chicken planted two tulip*(s).

(36) Tavuk iki lale-(*ler) dik-ti.

chicken two tulip-PL plant-PAST

'Chicken planted two tulips.'

Finally, as discussed in Ketrez (2003) and Görgülü (2012), among others, the Turkish plural can give rise to a 'plurality of events' reading and a 'plurality of types' reading, in addition to the regular 'plurality of individuals' one. For instance, (37) can be interpreted as suggesting that Ayşe engaged in multiple events of book-reading or that she read different types of books, in addition to the 'more than one book' reading. ${ }^{12}$

Ayşe kitap-lar oku-du.

Ayşe book-PL read-PAST

'Ayşe read books.'

The multiple-events interpretation is a rather marked interpretation of the plural and requires a particular context. ${ }^{13}$ In addition, such readings require an extra prosodic emphasis on the plural marker (Ketrez 2003). ${ }^{14}$

What is important for us is that these additional readings of the plural could in principle be the source of an inclusive interpretation. ${ }^{15}$ For instance, under the multiple-events reading, (37) is compatible with there being an event in which only one book is read by Ayşe, which in turn would give the impression of an inclusive reading, i.e., that Ayşe read one or more books. Note, however, that this source of 'inclusivity' is not predicted to be sensitive to polarity: the same reasoning can be extended to the corresponding negative sentence in (38) to obtain an inclusive reading in which there is no event of book reading, not even an event in which only one book is read.

\footnotetext{
12 As Ketrez (2003) discusses, a way to distinguish between these readings is with examples like (i), which pragmatically excludes the multiple-individual reading (i.e., there is only one Koran). The reading suggested by (i) can only be the multiple-events reading: Ayşe read the Koran multiple times.

(i) Ayşe Kuran-lar oku-du.

Ayşe Koran-PL read-PAst

'Ayşe read the Koran.'

13 For instance, according to the intuitions of the native speakers of Turkish among us, under that reading, (37) implies that Ayşe wanted to make someone happy by reading a book/books multiple times, and it is likely to be understood that Ayşe was unsuccessful in her attempt.

14 In the case of the negated verbs, the verb (which happens to be the syllable immediately preceding the negative morpheme) has to be stressed (e.g., Kabak and Vogel 2001), but this is incompatible with the extra stress of the plural marker. This could be a reason why the multiple-events reading is not intuitively possible in negative sentences.

15 Thanks to an anonymous reviewer for discussion on this point.
} 
In sum, while these other readings of the plural in Turkish could be the source of apparent inclusivity at least in some cases, they cannot account for sensitivity to monotonicity. We will return to this in the general discussion. ${ }^{16}$

\subsubsection{Theoretical options}

Let us return to the discussion on the existence of the inclusive meaning of the plural in Turkish. There are two approaches to the plural in Turkish, corresponding to the two positions in the literature sketched above.

Under the first approach, proposed in Bale et al. (2010) and Bale and Khanjian (2014), the plural ağaçlar ('trees') can only have the exclusive meaning in (39). Under the second approach, by Sağ $(2018,2019)$ and others, the plural has the inclusive meaning in (40), as in English, while the exclusive reading arises in one of the ways sketched above (i.e., via implicature, ambiguity, or homogeneity).

$$
\begin{aligned}
& \llbracket a \breve{g} a c ̧ l a r \rrbracket=\{\{a, b\},\{a, c\},\{b, c\},\{a, b, c\}\} \\
& \text { EXCLUSIVE MEANING } \\
& \llbracket a \breve{g} a c ̧ l a r \rrbracket=\{a, b, c,\{a, b\},\{a, c\},\{b, c\},\{a, b, c\}\}
\end{aligned}
$$

As above, we will refer to the latter approach as the inclusive approach, while we will call the former approach the exclusive approach, with the understanding that the former predicts both the inclusive and exclusive interpretations, while the latter only predicts the exclusive one.

How can we distinguish between these two approaches? One main case in which the predictions of the two approaches diverge is (41). In negative sentences, the inclusive approach, unlike the exclusive approach, predicts an inclusive reading, i.e., Chicken didn't plant any tulips (with blue petals). ${ }^{17}$

(41) Tavuk mavi yaprak-l1 lale-ler dik-me-di. chicken blue petal-with tulip-PL plant-NEG-PAST 'Chicken didn't plant tulips with blue petals.'

We will outline the predictions of the two approaches more systematically below. Before that, note that the exclusive approach simply predicts one meaning across polarities and does not need further assumptions, while the inclusive approach requires us to say something more about the alternation between the two readings in

\footnotetext{
16 Note also that the plural in Turkish can have an associative reading. That is, as has been noted by Sebüktekin (1971), Lewis (2000), Göksel and Kerslake (2005), and Görgülü (2011), the Turkish plural marker also has an associative use when attached to proper names and kinship nouns. For example, Yă̆mur-lar refers to the individual named Yă̆mur and other individuals associated with her, such as her friends or family. Since this use of the plural marker is restricted to proper names and kinship nouns only, we do not think this reading is relevant in our experiments.

17 The two approaches also make different predictions in other environments, like the scope of universals or that of non-monotonic quantifiers (see Spector 2007; Ivlieva 2013, among others, for relevant discussion). We leave an investigation of these other environments for future research.
} 
Fig. 1 The different theoretical options for the analysis of the Turkish plural

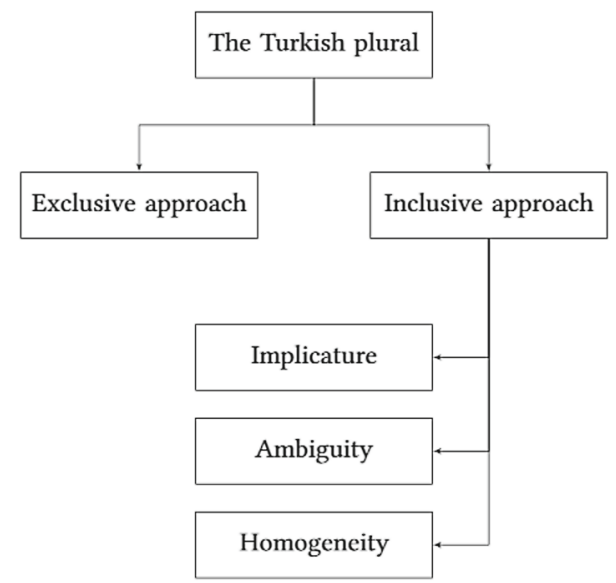

upward- and downward-entailing contexts and can be implemented in the three main ways discussed above, i.e., via implicature, ambiguity, and homogeneity. In other words, the theoretical landscape is as in Fig. 1: there is a first choice point between exclusive and inclusive approaches; if the latter path is taken, the choice is among the three accounts outlined above. In the following, we focus on the main predictions regarding the first choice, but we also discuss the predictions and the results of our experiments in relation to the specific predictions of the different accounts within the inclusive approach, based on discussion in Tieu et al. (2020) and Renans et al. (2018). We turn to this in the next section.

\section{Predictions}

\subsection{Main prediction: positive versus negative contexts}

As already mentioned, both the exclusive and inclusive approaches predict an exclusive reading of the plural in positive cases like (42), repeated from above.

This reading simply corresponds to the literal meaning of the plural on the exclusive approach, while it arises in one of the ways discussed above (i.e., via implicature, ambiguity, or homogeneity) on the inclusive approach. Either way, both approaches predict that the sentence in (42) will not be compatible with a context in which Chicken planted only one tulip with blue petals, as depicted in Fig. 2.

$$
\begin{array}{lllll}
\text { Tavuk } & \text { mavi } & \text { yaprak-li } & \text { lale-ler } & \text { dik-ti. } \\
\text { chicken } & \text { blue } & \text { petal-with } & \text { tulip-PL } & \text { plant-PAST }
\end{array}
$$

'Chicken planted tulips with blue petals.'

$\leadsto$ Chicken planted more than one tulip with blue petals

The two approaches make divergent predictions for plural nouns in negative sentences like (43): 
Fig. 2 Context for the sentences in (42) and (43) in which Chicken planted only one tulip with blue petals

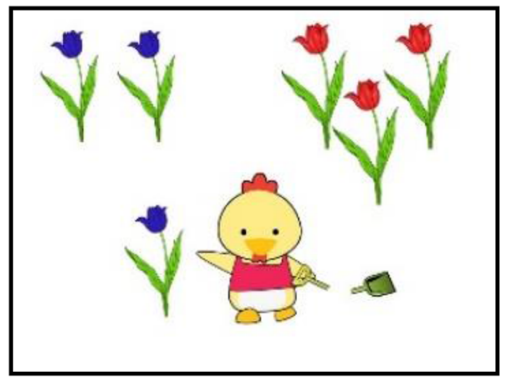

(43) Tavuk mavi yaprak-l1 lale-ler dik-me-di. chicken blue petal-with tulip-PL plant-NEG-PAST 'Chicken didn't plant tulips with blue petals.'

The exclusive approach only allows for exclusive readings of the plural; the only predicted reading of (43), then, is one we can paraphrase as Chicken didn't plant more than one tulip with blue petals. The exclusive approach therefore predicts (43) to be true in the context depicted in Fig. 2. By contrast, the inclusive approach makes more nuanced predictions for (43). First, as we discussed, the most prominent reading predicted for (43) is an inclusive reading which can be paraphrased as Chicken did not plant any tulips with blue petals, which is not compatible with the context depicted in Fig. 2. In addition, the inclusive approach also allows for a marked reading that corresponds to the negation of the exclusive reading (the same reading as predicted by the exclusive approach), which is compatible with the context depicted in Fig. 2.

A summary of the predictions of the exclusive and inclusive approaches for positive and negative sentences is outlined in Table 1 . These predictions will be the main focus of our experimental study.

\subsection{Additional predictions of the inclusive approach}

In this subsection, we further discuss the inclusive approach by considering the predictions of the different accounts within this kind of approach. If the inclusive approach is on the right track, these predictions will allow us to further distinguish among the three main accounts within the inclusive camp outlined above. We focus on two predictions in particular, having to do with the comparison between children and adults with respect to plurals and a corresponding implicature case.

Plurals The three accounts differ in the predictions they make for the acquisition of the plural and how children might differ from adults at a certain stage in their development (see Renans et al. 2018; Tieu and Romoli 2019; Tieu et al. 2020, for similar discussion).

Under the implicature approach, children are expected to behave roughly as they do with implicatures more generally. As has been reported in much previous developmental literature, 4-6-year-old children differ from adults in their computation of scalar implicatures (e.g., Noveck 2001; Papafragou and Musolino 2003; 
Table 1 Predictions of the exclusive and inclusive approaches regarding acceptance of the sentences Chicken planted tulips and Chicken didn't plant tulips in a context in which Chicken planted only one tulip

\begin{tabular}{lll}
\hline & Exclusive approach & Inclusive approach \\
\hline Chicken planted tulips. & $\times$ & $\times$ \\
Chicken didn't plant tulips. & $\boldsymbol{N}$ & $\times /(\boldsymbol{V})$ \\
\hline
\end{tabular}

' $x$ ' means that the sentence is predicted to be rejected in the given context and ' $\boldsymbol{V}$ ' means that the sentence is predicted to be accepted

Chierchia et al. 2001; among many others). Therefore, all else being equal, we expect a similar difference between the two groups when it comes to the exclusive reading of the plural as well, with children exhibiting fewer exclusive interpretations than adults.

Under the ambiguity approach, the predictions for children's acquisition of the plural depend on what assumptions are made about the acquisition of the proposed meanings for the plural and the Strongest Meaning Principle. That is, to be adult-like, children need to have acquired the two proposed meanings of the plural and the Strongest Meaning Principle to choose between them. There are, in particular, three main scenarios in which children might not be adult-like under this approach. They might go through a developmental stage where they have only acquired one of the two meanings of the plural (either the inclusive or the exclusive), or they might go through a stage where they have acquired both meanings for the plural but are not yet able to use the Strongest Meaning Principle in an adult-like way. These three possible scenarios are associated with different predictions for how children will respond to plural sentences, compared to adults. If children have only acquired the exclusive meaning of the plural, they should appear adult-like on the plural in positive sentences but not in negative ones; if they have only acquired the inclusive meaning of the plural, they should only appear adult-like in negative contexts. On the other hand, if they have acquired both meanings of the plural but cannot yet make use of a Strongest Meaning Principle in selecting a reading, they might not be guided by the relative strength of the two meanings of the plural in the same way that adults are.

Finally, in the case of the homogeneity approach, adult-like behaviour is dependent on children having acquired the homogeneity principle and the pragmatic principle for dealing with undefinedness. If they have acquired both, they should perform like adults; if they are missing either ingredient, they will not perform like adults. What is most relevant for us is that, as on the ambiguity approach, there is no clear way to distinguish between positive and negative contexts in this respect: either children will be adult-like in both contexts, or they will be non-adult-like in both of them.

Plurals versus implicatures Finally, let us outline a further prediction of the implicature-based account. This account argues that the exclusive reading of the plural arises as a scalar implicature and thus predicts a relationship between this reading and other kinds of scalar implicatures, especially in the context of the 
comparison between adults and young children. More specifically, as mentioned, it has been observed that young children typically compute fewer scalar implicatures than adults. Therefore, everything else being equal, if the exclusive reading of the plural is a scalar implicature, we expect that children should access this reading less than adults do. More generally, we expect a uniform pattern across groups when we compare the exclusive reading of the plural with standard scalar implicatures. The ambiguity and homogeneity accounts (and the exclusive approach for that matter), on the other hand, make no particular predictions about the relationship between implicatures and the inferences of plurals, since they do not relate the two phenomena.

In sum, while all three accounts of the plural within the inclusive approach make the same predictions regarding an effect of polarity, there are other areas where their predictions diverge. In particular, the theories make different predictions when it comes to the relative performance of children and adults regarding the inference of plurals. Moreover, the implicature approach makes predictions with respect to the relationship between the exclusive reading of the plural and standard implicatures.

\section{Experiment 1}

We tested the predictions discussed above by investigating Turkish speakers' interpretations of plural nouns in positive and negative sentences and comparing the plural to the scalar implicature of bazl 'some'. We employed the methodology used in the previous studies on English and Greek reported by Tieu et al. (2020) and Renans et al. (2018). Below, we also discuss how our results relate to theirs.

\subsection{Methods}

\subsubsection{Participants}

Forty-five adults and 22 children aged $4-6$ years (mean age 5;2), all native speakers of Turkish, participated in the experiment. We excluded from the analysis any participant who answered fewer than six of eight control trials correctly, which left us with a total of 42 adults and 21 children.

\subsubsection{Procedure}

At the beginning of the experiment, participants were introduced to a puppet with whom they would interact throughout the experiment via webcam. The appearances of the puppet in this set-up consisted of pre-recorded videoclips. Subsequently, the participants were presented with a series of short stories in a PowerPoint presentation. After each story, the experimenter posed a question to the puppet and the puppet replied with one of the test sentences. The participants' task was to judge the puppet's utterances by rewarding her with one, two, or three strawberries, depending on her performance (Katsos and Bishop 2011; Tieu et al. 2019a, b; Tieu 
et al. 2020). Participants were clearly instructed about the meaning of each reward: they were supposed to give the puppet one strawberry if they thought the puppet didn't answer well, three strawberries if they thought she answered well, and two strawberries if the puppet's answer was somewhere in the middle-not perfect, but somewhat okay.

\subsubsection{Materials}

Three factors were manipulated in the experiment: Group (child vs. adult), Sentence Type (Plural sentence vs. Scalar Implicature sentence), and Polarity (positive vs. negative) within the Plural condition. The materials for the Scalar Implicature condition and controls were translated to Turkish from the previous studies in English and Greek (reported in Tieu et al. 2020; Renans et al. 2018), while the materials for the Plural sentence condition were designed to be similar to these other conditions. The Plural and Scalar Implicature conditions were presented in blocks with the order counterbalanced across participants. Examples of positive and negative plural targets are presented in (44), with the corresponding picture in Fig. 3. ${ }^{18,19}$

(44) Plural target

Context: Tiger only planted this one tree and no flowers.

ExP: Peki, Ellie, Kaplan çiçek-ler ek-me-di. Peki, ağaç? okay Ellie tiger flower-PL plant-NEG-PAST what.about tree 'Okay, Ellie, so Tiger didn't plant any flowers. What about trees?'

a. Pupp: Kaplan ağaç-lar ek-ti. Positive tiger tree-PL plant-PAST 'Tiger planted trees.'

b. PupP: Kaplan ağaç-lar ek-me-di.

Negative tiger tree-PL plant-NEG-PAST 'Tiger didn't plant trees.'

Turning to the predictions, we note that both the exclusive and inclusive approaches predict an exclusive reading of the positive targets (i.e., 'Tiger planted more than one tree'). Since the exclusive reading was not true in the context, participants were expected to give the puppet a non-maximal reward, i.e., one or at most two strawberries.

\footnotetext{
18 To keep things interesting for the child participants, the characters and objects varied from one item to the next. The stories for the positive and negative conditions also differed.

19 We should flag right away that, as mentioned, most native speakers find non-case-marked unmodified bare plurals in object position infelicitous. We nevertheless decided to use them in this experiment, for the sake of maintaining uniformity with the previous studies on Greek and English. Using control items, we were able to confirm that participants were nonetheless interpreting the sentences in the expected way. But we acknowledge this potential issue with Experiment 1, and address it in Experiment 2 by moving to sentences with modified bare plurals in object position.
} 

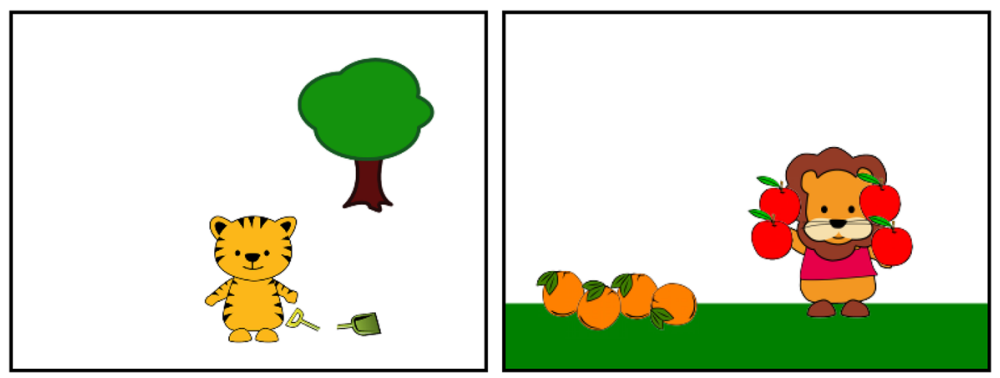

Fig. 3 Left: image for the plural targets in (44); right: image for the scalar implicature target in (45)

As for the negative targets, the exclusive approach predicts that participants should invariably access the exclusive plural interpretation of the noun (i.e., 'Tiger didn't plant more than one tree'). Given that this interpretation is true in the context, participants were expected to give the puppet the maximal reward, i.e., three strawberries. Under the inclusive approach, on the other hand, participants were expected to predominantly interpret the sentence inclusively (i.e., 'Tiger didn't plant any tree'). Since this interpretation is incompatible with the context, the expected reward was again one or at most two strawberries. In addition, the inclusive approach allows for a marked interpretation on which the exclusive reading is computed in the scope of negation (i.e., 'Tiger didn't plant more than one tree'). This interpretation is compatible with the context, so if participants accessed this reading, they were expected to give the puppet the maximal reward. In other words, the inclusive approach, but not the exclusive approach, allows for variability in participants' responses to the negative targets.

In the scalar implicature condition, the context made it clear that the action of the protagonist involved the whole set of objects depicted in the picture. When the experimenter asked the puppet what had happened in the story, she responded with a sentence containing the scalar term bazl 'some', as illustrated in (45) (the corresponding picture is provided in Fig. 3):

(45) Scalar Implicature target

Context: Lion carried all of the apples and none of the oranges.

ExP: $\quad$ Okay, Ellie, so Lion didn't carry any oranges.

What about apples?

PupP: Aslan elma-lar-1n bazı-lar-1-n1 taş1-d1.

Lion apple-PL-GEN some-PL-POSS.3sG-ACC carry-PAST

'Lion carried some of the apples.'

If participants interpreted the puppet's utterance with the scalar implicature of bazl 'some', i.e., 'Lion didn't carry all of the apples', they were expected to give the puppet one or two strawberries as a reward. By contrast, if they interpreted it literally, then they were expected to give the puppet the maximal reward.

The participants also received eight control trials to ensure that they could give minimal and maximal rewards where appropriate. Four of them corresponded to 
clearly true plural sentences and were expected to elicit the maximal reward, as in (46) and (47):

(46) Context: Giraffe did not bake any cakes but she baked four cookies.

ExP: Peki, Ellie, Zürafa kek-ler pişir-me-di. Peki, kurabiye? okay Ellie giraffe cake-PL bake-NEG-PAST what.about cookie 'Okay, Ellie, so Giraffe didn't bake any cakes. What about cookies?'

PupP: Zürafa kurabiye-ler pişir-di. Positive CONTROL Giraffe cookie-PL bake-PAST 'Giraffe baked cookies.'

(47) Context: Sheep baked four pizzas but no baklavas.

ExP: Peki, Ellie, Koyun pizza-lar pişir-di. Peki, baklava? okay Ellie sheep pizza-PL bake-PAST what.about baklava 'Okay, Ellie, so Sheep baked pizzas. What about baklavas?'

Pupp: Koyun baklava-lar pişir-me-di. Negative control Sheep baklava-PL bake-NEG-PAST 'Sheep didn't bake baklavas.'

Four other control trials corresponded to clearly true or clearly false negative sentences that contained a definite noun phrase instead of a bare plural. This allowed us to ensure that participants could correctly interpret negation independently of the bare plural. These trials could be associated with either a minimal or a maximal reward target; the experimenter selected the appropriate version of the trial depending on how participants responded to the critical target trials, balancing the overall number of minimal and maximal rewards given across the experiment.

(48) Context: Zebra painted four vases and no bowls.

ExP: Ellie, can you tell us something about the story?

PupP': Zebra kase-ler-i boya-ma-d1.

Zebra bowl-PL-ACC paint-NEG-PAST

'Zebra didn't paint the bowls.' (maximal reward target)

Pupp": Zebra vazo-lar-1 boya-ma-d1. NEGATIOn CONTROL

Zebra vase-PL-ACC paint-NEG-PAST

'Zebra didn't paint the vases.' (minimal reward target)

In sum, each participant received two training items followed by 18 test trials: 6 critical Plural targets ( 3 positive, 3 negative), 4 Scalar Implicature targets, 4 clearly true positive and negative Plural controls, and 4 clearly true or clearly false Negation controls. The Plural and Scalar Implicature targets were presented in blocks which were counterbalanced across participants; the test and control trials within the plural block were pseudo-randomised. 


\subsection{Results}

Figure 4 displays the proportion of 1-, 2-, and 3-strawberry responses to the Plural Positive, Plural Negative, and Scalar Implicature targets. At this stage, we group the non-maximal 1- and 2-strawberry responses together, in contrast to the 3-strawberry responses, mapping the reward types to different readings of the target sentences in the following way: for the Positive Plural targets, 1- and 2-strawberry responses are interpreted as a measure of the exclusive reading, while 3-strawberry responses correspond to an inclusive reading. For the negative Plural targets, the opposite holds: 3-strawberry rewards are interpreted as consistent with the exclusive reading, while 1- and 2-strawberry responses correspond to an inclusive reading. Finally, for the Scalar Implicature targets, 1- and 2-strawberry responses are interpreted as a measure of the target inference having been computed, whereas 3-strawberry rewards correspond to a non-implicature reading.

Starting with the positive Plural targets, we observe that adults mostly rejected the positive sentences in contexts that were incompatible with the exclusive reading. By contrast, children tended to accept such sentences in the same contexts, suggesting that they had instead interpreted the sentence under an inclusive reading. On the negative Plural targets, on the other hand, adults appeared to split between selecting the maximal and the non-maximal rewards, while children tended to give minimal rewards only, suggesting that they generally interpreted the plural inclusively under negation. Finally, in the Scalar Implicature condition, both groups generally selected non-maximal rewards, indicating that they computed the implicature of bazl 'some'.

Figure 5 displays the results for the positive and negative plural targets, with the ternary responses recoded in binary terms ( 1 for exclusive reading, 0 for inclusive

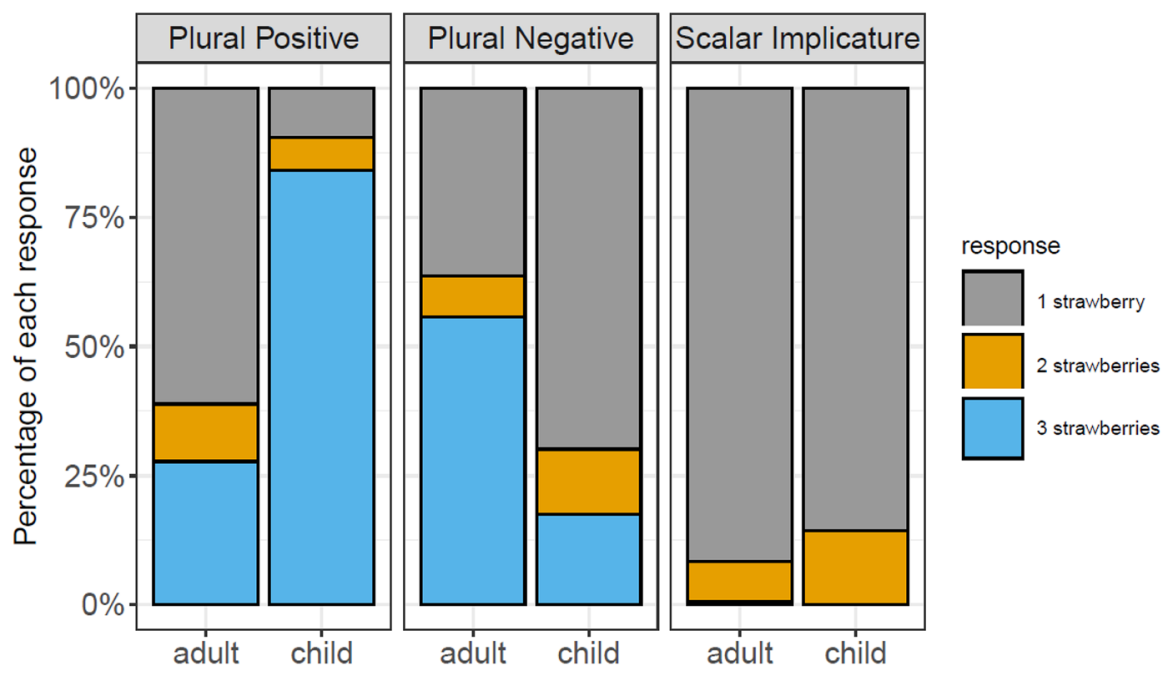

Fig. 4 Percentage of 1-, 2-, and 3-strawberry responses to positive and negative plural targets and scalar implicature targets 


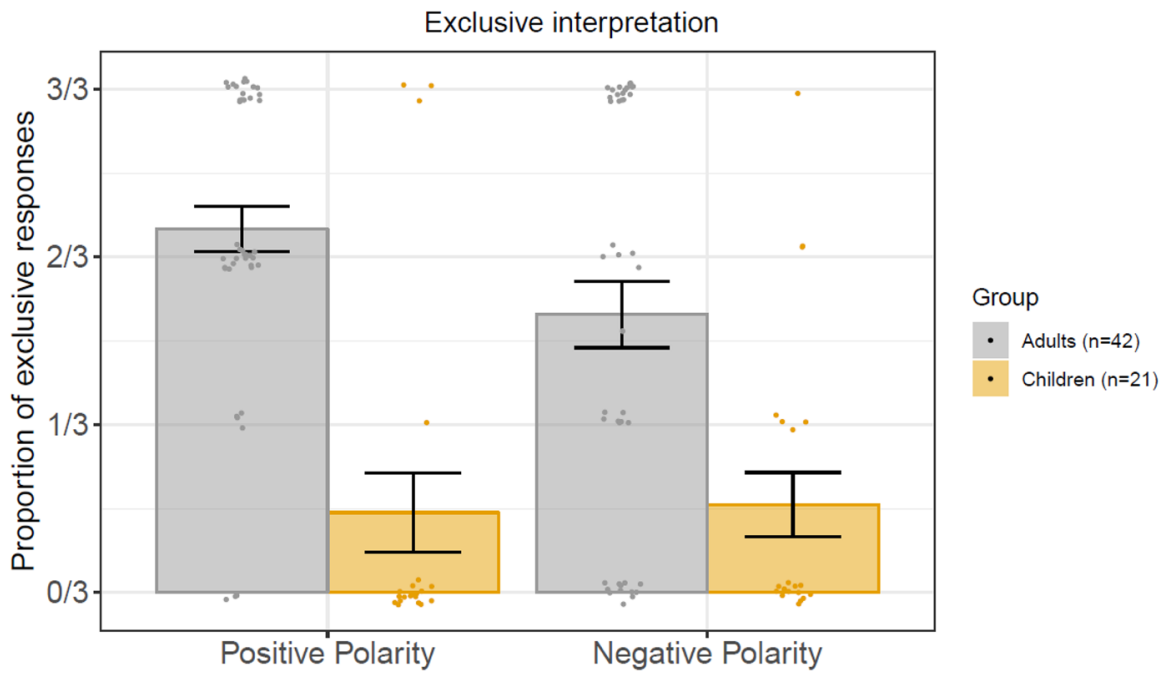

Fig. 5 Exclusive interpretations of positive and negative Plural targets after recoding of the ternary responses in binary terms ( 1 for the exclusive reading, 0 for the inclusive reading). Each dot represents an individual participant's mean inference rate for the given target

reading). Logistic regression models fitted to these recoded plural data revealed a significant effect of Group $\left(X^{2}(1)=29, p<0.001\right)$, but no effect of Polarity or interaction between Group and Polarity; that is, adults gave more exclusive responses than children did, and this difference between the two groups did not vary across the two polarities.

\subsection{Discussion}

Overall the results of Experiment 1 are in line with the predictions of the inclusive approach: adults gave clear evidence of an inclusive interpretation in negative contexts by rejecting the target sentence more than half of the time. The results are challenging for the exclusive approach, however, which predicts invariable acceptance in those contexts.

With respect to the additional predictions above, we found that children indeed exhibited fewer exclusive readings than adults did in positive contexts. This is in line with the general trend in the developmental literature on scalar implicatures, and hence this result is expected under the implicature account. However, the finding that children rejected the scalar implicature targets just as adults did is puzzling from this perspective and thus poses a challenge for the implicature account. $^{20}$

As for the ambiguity approach, it is compatible with children behaving differently on plurals and scalar implicatures, but it cannot account, at least not

\footnotetext{
${ }^{20}$ The challenge is in part mitigated by previous results in the literature revealing that rates of implicature computation vary widely across different scales (van Tiel et al. 2014). In the present case, this would mean that the some implicature is stronger than the exclusive reading of the plural in Turkish.
} 
straightforwardly, for the observed difference in children's behaviour on the positive and negative sentences. To illustrate, recall that on the ambiguity approach, a plural sentence is ambiguous between an exclusive and an inclusive reading, with the Strongest Meaning Principle determining which is selected. That is, a sentence like (49a) is ambiguous between the readings in (49b) and (49c), while the sentence in (50a) is ambiguous between the readings in (50b) and (50c). The Strongest Meaning Principle is expected to favour the strong reading in (49b) for (49a) and (50c) for (50a).

(49) a. Chicken planted tulips.

b. Chicken planted more than one tulip. STRONG

c. Chicken planted one or more tulips. WEAK

(50) a. Chicken didn't plant tulips.

b. Chicken didn't plant more than one tulip. WEAK

c. Chicken didn't plant one or more tulips. STRONG

The challenge for the ambiguity approach is as follows: while children seem to interpret positive sentences like (49a) on the weak reading in (49c), they preferred the strong interpretation in (50c) for negative sentences like (50a). It is unclear then how the ambiguity approach might capture this observed pattern across the polarities.

One possibility would be to assume that children have acquired both readings of plural sentences but engage with the Strongest Meaning Principle differently from adults. More precisely, they obey the principle in downward- but not in upwardentailing contexts. Such a scenario, however, appears implausible without further elaboration or auxiliary assumptions. In particular, while it is possible that children at a certain age might differ from adults in their use of a pragmatic principle like the Strongest Meaning Principle, there is no reason why they should be able to apply such a principle only in certain linguistic contexts. In particular, we can see no reason why their application of the principle would systematically vary with the polarity of the context.

Alternatively, under the ambiguity approach, one might hypothesise that children at a certain age have only acquired one of the two meanings of the plural morpheme. The scenario in which they have only acquired the strong exclusive meaning of the plural morpheme would predict the opposite pattern of what we observed in our experiment. This leaves us then with the scenario in which children in this age range have only mastered the weak inclusive meaning of plural morphology. This would indeed account for the pattern of behaviour that we observe, namely that children end up with a globally weak reading of the positive sentence in (49c) but a globally strong reading of the negative sentence in $(50 \mathrm{c})$ (since the weak interpretation of the plural morpheme yields the strongest interpretation under negation). This scenario, however, is also not free from challenges-in particular a learnability challenge. If 
the weak meaning is acquired first, how is the strong meaning then subsequently acquired without appropriate negative evidence? $?^{21,22}$

The results are also challenging for the homogeneity approach. In particular, it is unclear how to account for the finding that children were adult-like in response to the negative sentences but not to the positive ones. Under this approach, we would expect children to either have acquired the homogeneity principle and the pragmatic principle for dealing with undefinedness, and therefore to be adult-like in both the positive and negative conditions, or we would expect them not to have acquired either one and therefore to be non-adult-like in both conditions. It is not clear how to account for the observed difference across the two polarities. ${ }^{23}$

To summarise our discussion thus far, while the adults' data support the inclusive approach, the children's data are not straightforwardly in line with any of the three main accounts within this approach, and distinguishing among them requires further investigation.

Finally, the results are comparable to those reported by Tieu et al. (2020) and Renans et al. (2018) for English and Greek, respectively. There is, however, one key difference between the Turkish results and the findings from English and Greek, which lies in the relatively high acceptance rate of the negative targets in the Turkish experiment. While in the Turkish experiment adult participants accepted the negative sentence Tiger didn't plant trees $55 \%$ of the time in a context in which Tiger planted a single tree, in Tieu et al.'s English experiments and Renans et al.'s Greek experiment, the percentage of acceptance was generally lower (19-42\% in English, and $2 \%$ in Greek). We can think of two potential sources of this high

\footnotetext{
${ }^{21}$ This kind of subset problem is a much-discussed topic in the acquisition literature (see, for example, Berwick 1985; Crain et al. 1994; Gualmini and Schwarz 2009), and on the face of it would appear to pose a challenge for this choice point of the ambiguity theory.

${ }^{22}$ An anonymous reviewer points out that even if children engage differently from adults with the Strongest Meaning Principle, other principles of word learning or developmental biases regarding lexical ambiguity might play a role in explaining the observed pattern. We are not aware of any word learning principles or biases that would predict children to base meaning preferences for ambiguous sentences (containing lexically ambiguous words) on the monotonicity or other logical properties of the sentence. On the other hand, child learners are generally reported to prefer one-to-one form-meaning mappings and to have difficulty with homonyms (Markman 1990; Clark 1993; Backscheider and Gelman 1995), with some studies showing the ability to detect lexical ambiguity emerging only around the age of 6 years (Cairns et al. 2004) (though see Kamowski-Shakibai and Cairns 2016 for evidence that kindergarteners can be trained to detect lexical ambiguities); indeed, a number of studies focus on ambiguity detection in older, school-aged children, for instance on the role of ambiguity detection in reading abilities (Marmurek and Rossi 1993; Wankoff and Cairns 2009), or on the role of sentential context in lexical ambiguity resolution (Khanna and Boland 2010). If children do initially recognise only one of the possible meanings of the plural (namely the weak, inclusive meaning), this could explain why they prefer the globally weak reading of the positive sentences but the globally strong reading of the negative sentences. On the other hand, as we note above, in such a scenario it's not clear what evidence would eventually trigger the child to shift from having a weak/inclusive-only meaning for the plural to having both a weak/inclusive meaning and a strong/exclusive meaning. We agree with the reviewer, however, that the issue of lexical ambiguity in word learning could be quite relevant in this context and could make the predictions for the ambiguity approach more nuanced; we leave a more detailed investigation of this for future research.

${ }^{23}$ One could, for instance, posit that children differ from adults in how they deal with a sentence that is undefined in the context. The problem is that, given that the homogeneity approach predicts undefinedness in both the negative and positive conditions, we would need to assume that children deal with undefinedness differently for undefined positive sentences and undefined negative sentences.
} 
acceptance rate in the negative condition. First, it could be due to an interpretation in which the plural noun takes scope above negation. Second, it could be that the participants accessed the marked exclusive reading under negation, which is allowed, albeit dispreferred, under the inclusive approach. We next discuss these two possibilities in detail, before moving on to Experiment 2, designed to tease apart these hypotheses.

The scope of the plural Let us first consider the scope possibility. In English, bare plurals are generally only able to take narrow scope (e.g., Carlson 1977). For example, it is claimed in the literature that the only possible reading of (51) is one in which the plural doctors is in the scope of want:

(51) Mary wants to meet doctors.

(Carlson 1977)

$\approx$ Mary wants to meet some doctors or other (not a specific set of doctors)

(WANT $>$ DOCTORS)

By contrast, bare plurals have been argued to be able to take wide scope in Turkish (Bliss 2004; see also Bale and Khanjian 2014). For example, (52) has been claimed to allow two interpretations, depending on the scopal relation between the bare plural doktorlar 'doctors' and istiyor 'want'. If 'doctors' scopes below 'want', then the predicted reading is the same as in English, i.e., (52a). But when 'doctors' scopes above 'want', then the predicted reading is as in (52b), that is, Mary wants to meet a specific set of doctors.

(52) Mary doktor-lar bul-mak isti-yor. (from Bliss 2004: 51)

Mary doctor-PL meet-INF want-PROG

'Mary wants to meet doctors.'

a. $\approx$ Mary wants to meet some doctors or other $\quad$ (WANT $>$ PL)

b. $\approx$ There are some doctors that Mary wants to meet (PL $>$ WANT)

This suggests that a negative sentence containing a bare plural in Turkish, such as (53), might also in principle give rise to the two interpretations depending on the scopal relation between the plural and negation.

(53) Kaplan ağaç-lar ek-me-di.

tiger tree-PL plant-NEG-PAST

'Tiger didn't plant trees.'

a. $\approx$ It's not true that Tiger planted trees $\quad($ NEG $>$ PL)

b. $\approx$ There are some trees that Tiger didn't plant $(\mathrm{PL}>\mathrm{NEG})$

If indeed the sentence in (53) was sometimes interpreted as in (53b), and since our contexts were compatible with this interpretation, this could explain the relatively high proportion of acceptance of the negative targets. 
Favouring the marked interpretation through contrastive focus The second possible explanation for the high acceptance rate of the negative sentences in Turkish could be due to some factor facilitating the generally dispreferred exclusive reading under negation; as we have discussed, this reading is always a possibility when forced by the context. In particular, the English and Greek experiments differed from the present Turkish experiment in one potentially important respect: in both the English and Greek experiments, the experimenter asked the puppet a question using a bare plural and then the puppet replied using a bare plural noun as well, as seen in the English example in (54). In the Turkish experiment, however, the experimenter asked the puppet a question using a morphologically singular noun and the puppet replied using a bare plural noun, as in (55) (although we used the plural paraphrases for our English translations in examples (44)-(47)):

(54) ExP: Tiger didn't plant any flowers. What about trees? ENGLISH Pupp: Tiger didn't plant trees.

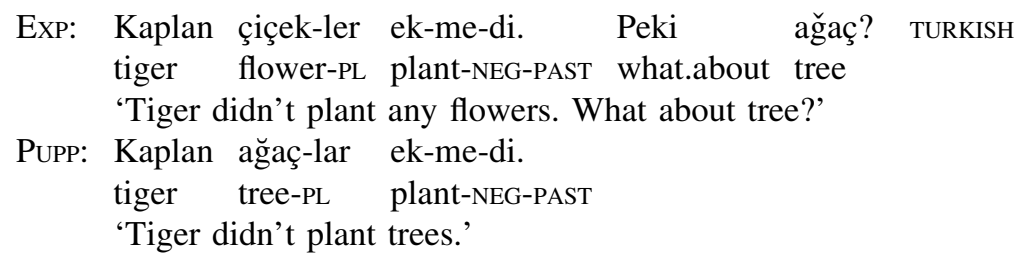

This contrast between the singular noun in the question and the plural noun in the answer could have encouraged a contrastive focus interpretation of the plural and facilitated the otherwise dispreferred exclusive interpretation of the plural under negation. That is, "Tiger didn't plant trees" would be interpreted as 'Tiger didn't plant TREES' ( $\approx$ Tiger didn't plant more than one tree). If so, this could account for the higher acceptance of the negative sentences, as this interpretation was compatible with the given context.

In order to tease apart these different hypotheses, we conducted a follow-up study to Experiment 1, which we present in the next section.

\section{Experiment 2}

The aim of Experiment 2 was two-fold. First, we wanted to investigate in more detail the finding of greater acceptance of the negative targets in Experiment 1, as discussed in the last section. Second, we wanted to address the potential issue of the acceptability of sentences with unmodified bare plurals and replicate the results with more natural sentences involving modified plurals. 


\subsection{Methods}

\subsubsection{Participants}

We tested 40 adult native speakers of Turkish. Two participants were excluded from the analysis for failing to correctly answer at least six of the eight control items, leaving a total of 38 participants.

\subsubsection{Procedure}

The procedure was exactly the same as in Experiment 1.

\subsubsection{Materials}

The design was different from that of Experiment 1 in three respects. First, we used target sentences involving modified bare plurals, as in (56).

(56) Tavuk mavi yaprak-l1 lale-ler dik-me-di. chicken blue petal-with tulip-PL plant-NEG-PAST 'Chicken didn't plant tulips with blue petals.'

Second, we changed the question that the experimenter asked the puppet so as not to facilitate a contrastive focus interpretation that could lead to the exclusive reading under negation. The new type of question was as in (57):

$$
\begin{aligned}
& \text { Bize hikaye hakkında birşey-ler söyle-r mi-sin? } \\
& \text { us story about something-PL say-AOR QUEST-2SG } \\
& \text { 'Can you tell us something about the story?' }
\end{aligned}
$$

Third, we manipulated scope such that half of the negative targets made a widescope interpretation of the plural noun true (Wide-Scope-True contexts) and half made the wide scope interpretation false (Wide-Scope-False contexts). An example of a target sentence in a Wide-Scope-True context is provided in (58); the corresponding image is provided in Fig. 6. In this example, it is true that there are tulips with blue petals that Chicken didn't plant.

An example of a target sentence in a Wide-Scope-False context is given in (59); the corresponding image is provided in Fig. 6. In this example, the wide-scope interpretation (i.e., 'There are books with green covers that Tiger didn't buy') is false (assuming that the wide-scope reading would give rise to an exclusive interpretation, i.e., 'There is more than one book with a green cover that Tiger didn't buy', as would be expected by any of the approaches, given that the plural would not be in the scope of negation). 

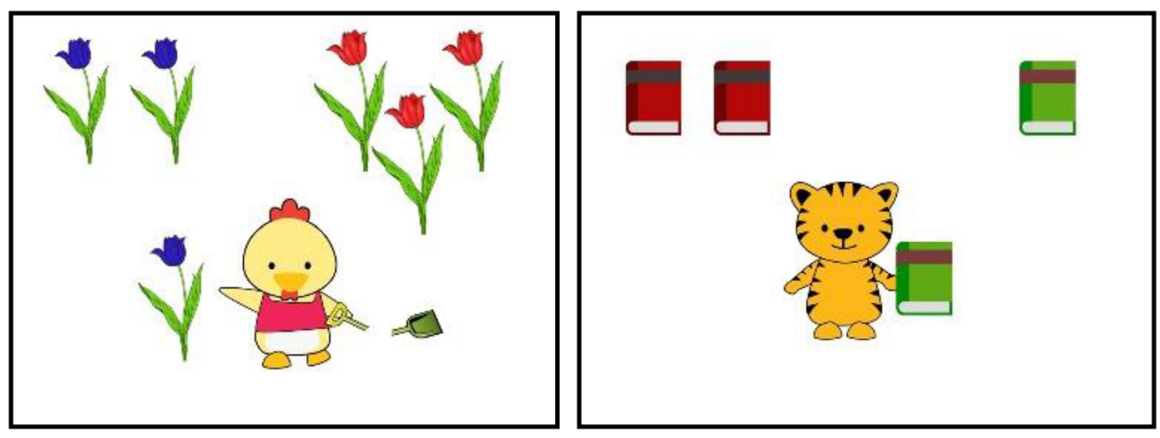

Fig. 6 Target image for (58) (left) and (59) (right)

(58) Wide-Scope-True target

Context: Chicken only planted this one tulip with blue petals over here.

ExP: Okay, Ellie, can you tell us something about the story?

PuPP: Tavuk mavi yaprak-l1 lale-ler dik-me-di. chicken blue petal-with tulip-PL plant-NEG-PAST

'Chicken didn't plant tulips with blue petals.'

(59) Wide-Scope-False target

Context: Tiger only bought this one book with a green cover over here.

ExP: Okay, Ellie, can you tell us something about the story?

PupP: Kaplan yeşil kapak-l1 kitap-lar al-ma-d1.

Tiger green cover-with book-PL buy-NEG-PAST

'Tiger didn't buy books with green covers.'

As in Experiment 1, participants also received eight control items to ensure that they could give minimal and maximal rewards where appropriate. Unlike in Experiment 1 , however, participants were not presented with scalar implicature targets. To sum up, each participant received six positive plural targets, six negative plural targets (three in Wide-Scope-True contexts and three in Wide-Scope-False contexts), and eight controls.

The predictions of the scope and contrastive focus hypotheses were as follows. First, if scope played a role in the interpretation of the plural in Experiment 1, we expected to observe a different response pattern in the Wide-Scope-True and WideScope-False conditions in Experiment 2. Second, if the singular question in Experiment 1 facilitated an exclusive interpretation under negation, we expected more rejections of the negative targets in Experiment 2 compared to Experiment 1.

\subsection{Results}

Figure 7 displays the proportion of 1-, 2-, and 3-strawberry responses to the positive and negative targets, in Wide-Scope-True and Wide-Scope-False conditions. As in Experiment 1, the non-maximal 1- and 2-strawberry responses were treated alike, in 


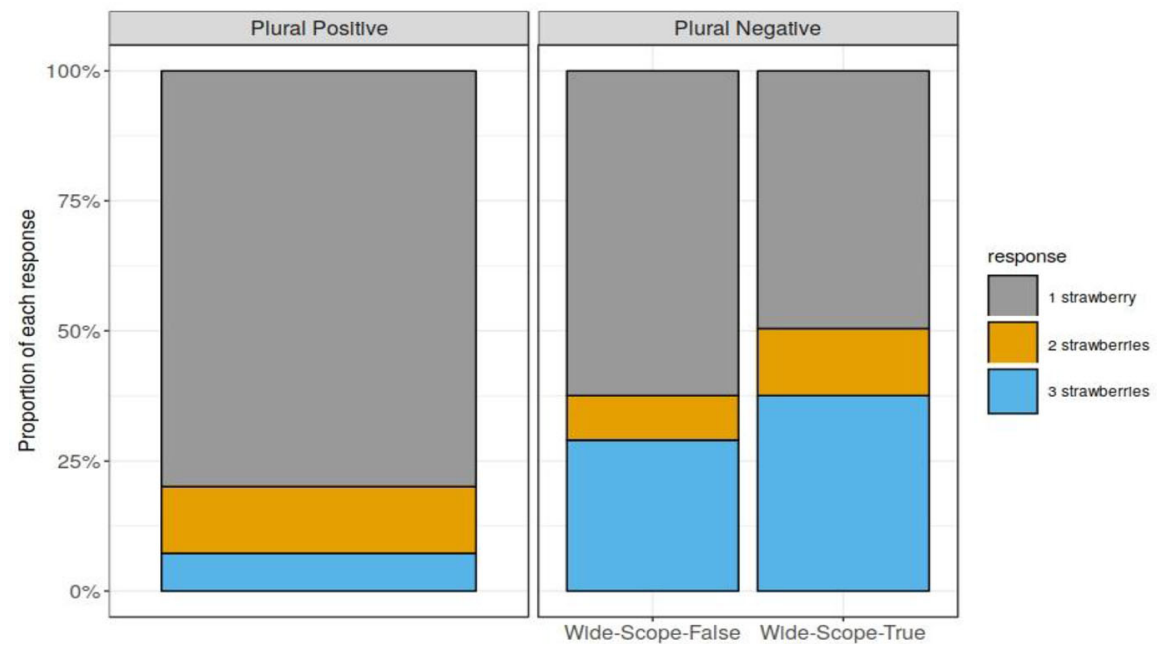

Fig. 7 Proportion of 1-, 2-, and 3-strawberry responses across conditions

contrast to the 3-strawberry responses. As before, for the positive plural targets, 1and 2-strawberry responses were interpreted as a measure of the exclusive reading, while 3-strawberry responses corresponded to an inclusive reading. For the negative plural targets, 3-strawberry rewards were interpreted as being compatible with the exclusive reading, while 1- and 2-strawberry responses corresponded to an inclusive reading.

As we can see, similarly to Experiment 1, the participants mostly rejected the positive sentences in contexts that were incompatible with the exclusive reading. On the plural negative targets, the participants also tended to give the puppet nonmaximal rewards, in this case suggesting access to the inclusive reading. Figure 8 displays the results for the positive and negative plural targets (both Wide-ScopeFalse and Wide-Scope-True targets), with the ternary responses recoded in binary terms ( 1 for the exclusive reading, 0 for the inclusive reading). Logistic regression models fitted to these data revealed a significant effect of Polarity $\left(X^{2}(1)=34, p<0.001\right)$ : the participants gave more exclusive responses to the positive targets than to the negative targets-an effect that was not observed in Experiment 1.

Figure 9 presents the results for the Wide-Scope-True and Wide-Scope-False negative targets, with the ternary responses recoded in binary terms ( 1 for the exclusive reading, 0 for the inclusive reading). Logistic regression models fitted to these data revealed no effect of scope.

\subsection{Discussion}

The results of Experiment 2 provide further support for the inclusive approach. In particular, we found no evidence that scope played a role in Experiment 1, in terms of explaining the relatively high acceptance of the negative plural targets. The 


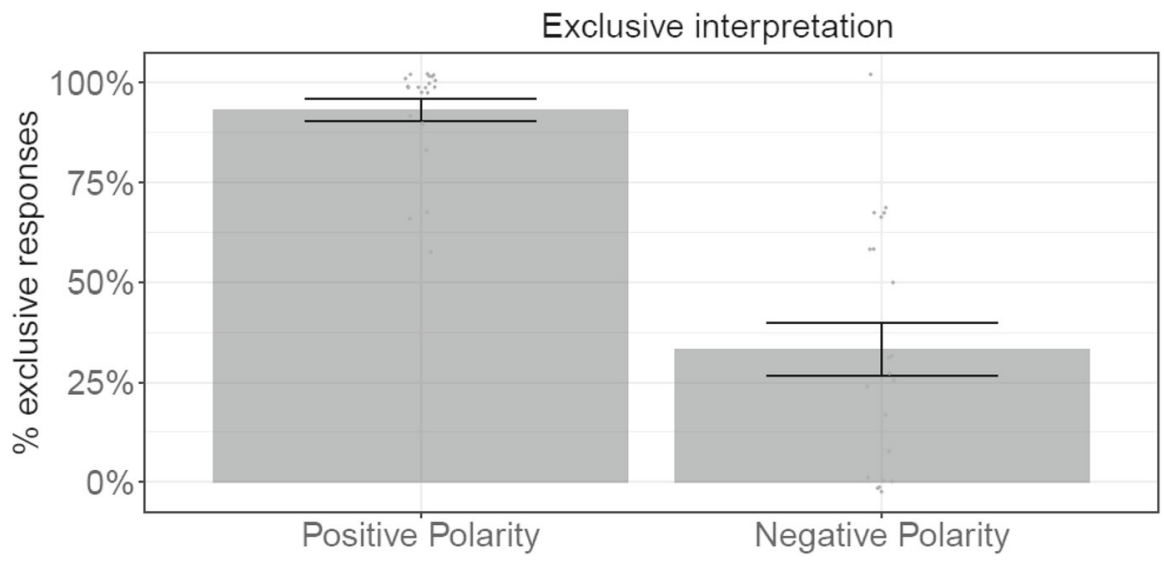

Fig. 8 Percentage of exclusive responses in positive and negative conditions, after recoding of the ternary responses in binary terms ( 1 for the exclusive reading, 0 for the inclusive reading). Each dot represents an individual participant's exclusive response rate for the given target

participants in Experiment 2 mostly rejected the sentences in the negative condition, whether they were presented in Wide-Scope-True or Wide-Scope-False contexts.

In addition, after changing the experimenter's question to the puppet so that it would not encourage the otherwise dispreferred exclusive reading under negation, acceptance of the negative sentences decreased from 55\% in Experiment 1 to 33\% in Experiment 2. Experiment 2 revealed an effect of polarity that was absent in Experiment 1, with more exclusive interpretations in the positive than in the negative conditions. The difference between Experiment 1 and Experiment 2 suggests that the experimenter's question containing the singular in Experiment 1 influenced participants' acceptance of the negative plural targets.

Finally, as mentioned above, while the multiple-events/types readings of the plural could be the source of some of the apparent inclusivity in Turkish, these readings cannot account for the difference we found between positive and negative sentences, especially in Experiment 2. Therefore, while we cannot exclude that some of the observed inclusive interpretations can be traced back to these other readings, they cannot be the only factor behind these interpretations. ${ }^{24}$

\footnotetext{
${ }^{24}$ An anonymous reviewer asks whether our data are compatible with a subset of the adult participants having only an exclusive interpretation of the plural. While we cannot exclude that there was a subgroup of our adult participants who consistently responded with an exclusive interpretation of the plural, we would caution against extrapolating from this to a more general claim that these speakers could only access exclusive interpretations of the plural. In addition, although we show individual dot points in Figs. 5 and 8, our main arguments (and reported statistical evidence) are based on the group results. We do not wish to draw strong conclusions based on individual responses, especially as each participant only received three plural targets of each polarity. On the basis of the group results, the fact that the rate of exclusive responses is lower in Experiment 2 (Fig. 8) (33\%, vs. 55\% in Experiment 1) suggests that there was an effect of the singular in the experimenter's question in Experiment 1-this is another reason not to draw strong conclusions about the 'exclusive-only' individual response pattern in Experiment 1 . Finally, as seen in Fig. 8, there were far fewer individual participants who only gave exclusive responses in Experiment 2 compared to Experiment 1, further decreasing the plausibility that there was a group of speakers who could only access exclusive interpretations of the plural.
} 


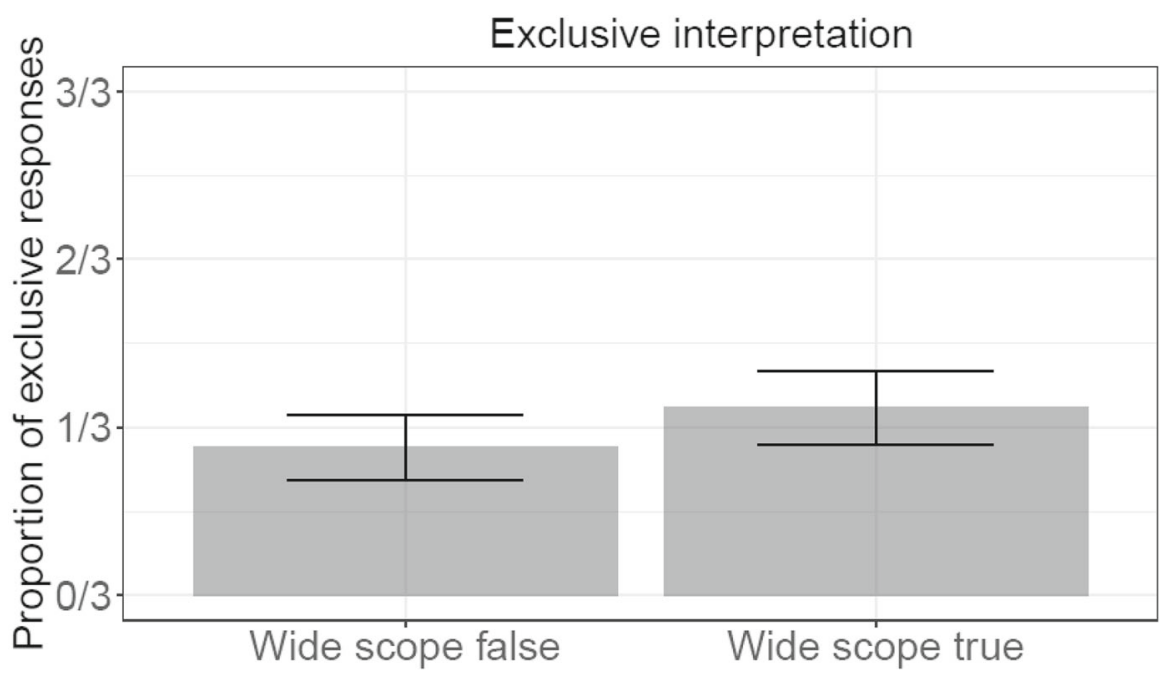

Fig. 9 Proportion of exclusive responses in the Wide-Scope-True and Wide-Scope-False negative conditions, after recoding of the ternary responses in binary terms ( 1 for the exclusive reading, 0 for the inclusive reading)

\section{General discussion}

The results of our experiments provide support for the inclusive approach to the interpretation of the plural in Turkish. The findings suggest that, in this respect, the Turkish plural is not so different from the English (or Greek) plural after all. In addition, as we discussed, while our results are in line with the inclusive approach, the children's behaviour in Experiment 1 was not entirely expected under any of the accounts within this approach (implicature, homogeneity, or ambiguity). Understanding how to best implement the inclusive approach to account for the Turkish plural and its acquisition will therefore require further investigation.

The question now is how the inclusive approach to the plural can be integrated with a more general theory of number in Turkish. As already discussed in Sect. 2.2, there are two main properties of the Turkish number system that make it different from that of English. The first has to do with inclusive interpretations of the singular, while the second has to do with the obligatory agreement between the singular and numerals. Our main point is that one does not need to assume an exclusive approach to Turkish to account for the properties of its number system. In other words, these other properties of the Turkish plural do not force an exclusive approach and are instead perfectly compatible with the inclusive one. This is relevant for us for two reasons. First, certain explanations of these phenomena in the literature (e.g., Bale and Khanjian 2014) rely on a purely exclusive interpretation of the plural and implicitly suggest that the latter is required to account for the relevant facts. Second, many versions of the inclusive approach to the plural assume some form of competition with the singular, associated with a singular non-inclusive interpretation. As we show below, however, there exist possible accounts of the two 
phenomena of the Turkish number system which are independent from the assumption about the plural and thus readily compatible with the inclusive approach.

\subsection{Bare singulars}

Let us first discuss the observation that Turkish bare singulars can give rise to an inclusive interpretation when in a non-case-marked direct object position (Bliss 2004; Görgülü 2012; Martí 2020a; Să̆ 2018, 2019), as in (60). Here we follow Săg $(2018,2019)$ (see also Martí 2020b), who argues that the inclusive interpretation of bare singulars is a simple by-product of pseudo-incorporation, rather than arising directly from the denotation of the singular (Massam 2001). ${ }^{25}$ Pseudo-incorporated nouns differ from canonical arguments, such as definites, quantified expressions, etc., in that they form a syntactic unit with the verb immediately preceding them and do not receive case marking (Öztürk 2005; Să̆ 2018, 2019).

(60) Ali kitap oku-du.

Ali book read-PAST

'Ali did book-reading (one or more books).'

Sağ (2019) argues that bare singulars in Turkish are singular terms, denoting sets of atoms, and that the apparent number neutrality in the case shown above follows from their singular kind reference. The gist of Sağ's account is that pseudoincorporated bare singulars are singular kind terms that are incorporated to the verb via a special thematic function to yield a sub-event type interpretation (cf. Sağ 2018; Dayal 2011, 2015). For example, in (60), Ali is involved in the book-reading event as an agent, and the existence of a book-reading event type generates the interpretation of reading one or more books, the instantiations the singular kind is associated with. ${ }^{26}$ Of relevance for our purposes is that this account maintains that the interpretation of the singular is simply a set of atomic individuals, which is compatible with an inclusive approach to the plural. That is, the apparent number neutrality of the singular doesn't force an exclusive approach to the plural in Turkish. $^{27}$

\footnotetext{
$\overline{25}$ See also Sağ (2019) for syntactic and semantic arguments against extending a pseudo-incorporation analysis from bare singulars to bare plurals in Turkish.

${ }^{26}$ Sağ $(2018$, 2019) follows Dayal (2004) in that singular kinds are impure atomic taxonomic kinds that do not allow grammatical access to instantiation sets via type-shifting operators like pred. The relation between a singular kind and its instantiations, therefore, is established at the conceptual level. However, Sağ (2019) argues that pseudo-incorporation in Turkish establishes this relation in the grammatical component.

${ }^{27}$ Existential copular constructions that are roughly translated into English as 'have'-predicates are another place where bare singulars have number-neutral interpretations. Sağ (2019) considers them an instance of pseudo-incorporation. In addition, the claim made in Bale et al. (2010) is based on the ability of bare singulars to occur in the predicate position of both singular and plural subject terms. In Sağ $(2018,2019)$, this is argued to follow from the fact that they occur as singular kind terms in this position, rather than from their alleged number neutrality. They participate in kind specification constructions in which the subject term is associated with a kind it belongs to, regardless of its number.
} 


\subsection{Numerals and number marking}

As mentioned, numerals in Turkish, unlike in English, do not combine with bare plurals but rather with bare singulars, as shown in (61). This disparity is particularly surprising under the assumption, defended above, that the denotations of singulars and plurals are the same in both languages.

\section{(61) iki kitap-(*lar) \\ two book-PL \\ 'two books'}

Bale et al. (2010) give an account of cases like (61) based on their number-neutral treatment of bare singulars and their exclusive approach to bare plurals. Here again we want to sketch how alternative proposals to the facts in (61) are compatible with an inclusive approach to the plural instead. In other words, the idiosyncratic interaction between numerals and number in Turkish doesn't necessitate an exclusive approach to the plural.

We sketch Sağ's (2018) proposal as an example of an account which is compatible with the inclusive approach to the plural; see also Martí (2020b) and Scontras (2014) for similar accounts. Sağ's proposal is based on Ionin and Matushansky's (2006) analysis of numerals as modifiers, the lexical complement of which has to be atomic. Ionin and Matushansky (2006) claim that in languages like English, numeral constructions exhibit number agreement (semantic concord). That is, $-s$ in two books would not be a genuine plural marker, but rather the realisation of number agreement. Importantly, true plurals cannot combine with numerals because only individuals of the same cardinality can be counted. By contrast, the plural marker in Turkish (-lar), as in kitaplar, would be a genuine plural marker. Since kitaplar denotes a set of plural individuals of different cardinalities, it cannot combine with numerals. On the other hand, as singular nouns would denote sets of atoms, under this approach they are able to combine with numerals. Again, this shows that there is a way to account for the numeral facts in Turkish that can be combined with the inclusive approach to the plural.

\section{Conclusions}

In English and many other languages, plural nouns are associated with two possible readings: an exclusive reading in positive contexts and an inclusive reading in negative ones. By contrast, Turkish is generally cited as a language in which the plural only has an exclusive interpretation. In this paper, we reported two experiments conducted with Turkish-speaking adults and 4-6-year-old children, the results of which suggest that the Turkish plural is in fact similar to the English plural in this respect: it gives rise to the exclusive interpretation in positive contexts and to the inclusive one in negative contexts. This result supports an inclusive approach to the plural in Turkish (Sağ 2018, 2019, among others). Notably, however, while our results are in line with the inclusive approach, the children's behaviour in Experiment 1 was not entirely expected 
under any of the accounts within this approach (implicature, homogeneity, or ambiguity). Understanding how best to implement the inclusive approach to account for the Turkish plural and its acquisition therefore requires further investigation.

We also discussed how this approach to the plural can be integrated into a theory of the Turkish number system. This is important beyond understanding the properties of the Turkish number system, as it can tell us more about the different meanings that the plural can obtain across languages, thereby furthering our understanding of number marking and its crosslinguistic variation. In particular, the main question in the background of our study is whether there is any language that only allows an exclusive interpretation of the plural. Our results suggest that Turkish is not such a language. We hope our study will pave the way for further experimental investigation of languages like Western Armenian and Korean, which are other possible candidates for languages with exclusive-only plurals.

Acknowledgements Open Access funding provided by Projekt DEAL. For helpful feedback and discussion, we would like to thank Amir Anvari, Julie Gerard, Matt Mandelkern, Luisa Martí, Christina Sevdali, and audiences in Potsdam, Belfast, Tübingen, and at the Amsterdam Colloquium 2017. We are also grateful to Dorothy Ahn for allowing us to use her artwork in our experimental stimuli and to Istanbul Bilgi University students for participation in the experiments. This work was partially funded by the Leverhulme Trust Grant RPG-2016-100.

Open Access This article is licensed under a Creative Commons Attribution 4.0 International License, which permits use, sharing, adaptation, distribution and reproduction in any medium or format, as long as you give appropriate credit to the original author(s) and the source, provide a link to the Creative Commons licence, and indicate if changes were made. The images or other third party material in this article are included in the article's Creative Commons licence, unless indicated otherwise in a credit line to the material. If material is not included in the article's Creative Commons licence and your intended use is not permitted by statutory regulation or exceeds the permitted use, you will need to obtain permission directly from the copyright holder. To view a copy of this licence, visit http:// creativecommons.org/licenses/by/4.0/.

\section{References}

Backscheider, Andrea G., and Susan A. Gelman. 1995. Children's understanding of homonyms. Journal of Child Language 22 (1): 107-127.

Bale, Alan, and Hrayr Khanjian. 2009. Classifiers and number marking. In Semantics and linguistic theory (SALT) 18, ed. T. Friedman and S. Ito, 73-89. Ithaca, NY: CLC Publications.

Bale, Alan, and Hrayr Khanjian. 2014. Syntactic complexity and competition: The singular-plural distinction in Western Armenian. Linguistic Inquiry 45 (1): 1-26.

Bale, Alan, Michaël Gagnon, and Hrayr Khanjian. 2010. Cross-linguistic representations of numerals and number marking. In Semantics and linguistic theory (SALT) 20, ed. Nan Li and David Lutz, 582-598. Ithaca, NY: CLC Publications.

Berwick, Robert C. 1985. The acquisition of syntactic knowledge. Cambridge, MA: MIT Press.

Bliss, Heather. 2004. The semantics of the bare noun in Turkish. Calgary Papers in Linguistics 25 (1): $1-65$.

Bylinina, Lisa, and Alexander Podobryaev. 2020. Plurality in Buriat and structurally constrained alternatives. Journal of Semantics 37 (1): 117-128.

Cairns, Helen S., Dava Waltzman, and Gloria Schlisselberg. 2004. Detecting the ambiguity of Sentences: Relationship to early reading skill. Communication Disorders Quarterly 25 (2): 68-78.

Carlson, Gregory N. 1977. Reference to kinds in English. PhD dissertation, University of Massachusetts at Amherst.

Chierchia, Gennaro. 2010. Mass nouns, vagueness and semantic variation. Synthese 174: 99-149. 
Chierchia, Gennaro, Stephen Crain, Maria T. Guasti, and Rosalind Thornton. 2001. 'Some' and 'or': A study on the emergence of logical form. In Proceedings of the 22nd Boston University conference on language development, ed. A. Greenhill et al., 97-108. Somerville, MA: Cascadilla Press.

Clark, E.V. 1993. The lexicon in acquisition. Cambridge: Cambridge University Press.

Crain, Stephen, Weijia Ni, and Laura Conway. 1994. Learning, parsing, and modularity. In Perspectives on sentence processing, ed. Charles Clifton Jr., Lyn Frazier, and Keith Rayner, 443-467. Hillsdale, NJ: Lawrence Erlbaum.

Dayal, Veneeta. 2004. Number marking and indefiniteness in kind terms. Linguistics and Philosophy 27 (4): $393-450$.

Dayal, Veneeta. 2011. Hindi pseudo-incorporation. Natural Language \& Linguistic Theory 29 (1): $123-167$.

Dayal, Veneeta. 2015. Incorporation: Morpho-syntactic vs semantic considerations. In The syntax and semantics of pseudo-incorporation (Syntax and semantics 40), ed. O. Borik and B. Gehrke, 47-87. Leiden: Brill.

Farkas, Donka, and Henriette de Swart. 2010. The semantics and pragmatics of plurals. Semantics \& Pragmatics 3 (6): 1-54.

Göksel, Asl1, and Celia Kerslake. 2005. Turkish: A comprehensive grammar. London: Routledge.

Görgülü, Emrah. 2011. Plural marking in Turkish: Additive or associative? Working Papers of the Linguistics Circle of the University of Victoria 21, 70-80.

Görgülü, Emrah. 2012. Semantics of nouns and the specification of number in Turkish. PhD dissertation, Simon Fraser University.

Grice, Paul. 1975. Logic and conversation. In The logic of grammar, ed. Donald Davidson and Gilbert H. Harman, 64-75. Encino, CA: Dickenson Publishing Company.

Grimm, Scott. 2013. Plurality is distinct from number-neutrality. In Proceedings of the 41st meeting of the North East Linguistic Society (NELS 41), ed. Yelena Fainleib, Nicholas LaCara, and Yangsook Park, 247-258. Amherst, MA: GLSA Publications.

Gualmini, Andrea, and Bernhard Schwarz. 2009. Solving the learnability problems in the acquisition of semantics. Journal of Semantics 26: 185-215.

Ionin, Tania, and Ora Matushansky. 2006. The composition of complex cardinals. Journal of Semantics 23 (4): 315-360.

Ivlieva, Natalia. 2013. Scalar implicatures and the grammar of plurality and disjunction. PhD dissertation, MIT.

Kabak, Barış, and Irene Vogel. 2001. The phonological word and stress assignment in Turkish. Phonology 18: 315-360.

Kamowski-Shakibai, Margaret T., and Helen S. Cairns. 2016. Kindergarten children can be taught to detect lexical ambiguities. Journal of Child Language 43 (2): 442-456.

Kan, Seda. 2010. Number marking and Turkish noun phrases. Manuscript, University of Massachusetts at Amherst.

Katsos, Napoleon, and Dorothy V.M. Bishop. 2011. Pragmatic tolerance: Implications for the acquisition of informativeness and implicature. Cognition 120 (1): 67-81.

Ketrez, Nihan. 2003. -1Ar-marked nominals and three types of plurality in Turkish. In Proceedings of the Chicago Linguistics Society 39, 176-192. Chicago: CLS.

Khanna, Maya M., and Julie E. Boland. 2010. Children's use of language context in lexical ambiguity resolution. Quarterly Journal of Experimental Psychology 63 (1): 160-193.

Krifka, Manfred. 1989. Nominal reference, temporal constitution and quantification in event semantics. In Semantics and contextual expressions, ed. Renate Bartsch, Johan van Benthem, and Peter van Emde Boas, 75-116. Dordrecht: Foris.

Križ, Manuel. 2015. Aspects of homogeneity in the semantics of natural languages. PhD dissertation, University of Vienna.

Križ, Manuel. 2017. Bare plurals, multiplicity, and homogeneity. Manuscript, Institut Jean Nicod.

Lewis, G.L. 2000. Turkish grammar, 2nd ed. Oxford: Oxford University Press.

Markman, Ellen M. 1990. Constraints children place on word meanings. Cognitive Science 14 (1): 57-77.

Marmurek, Harvey H.C., and Mary Rossi. 1993. The development of strategic processing of ambiguous words: Riddles versus neutral context. The Journal of Genetic Psychology 154 (4): 475-486.

Martí, Luisa. 2020a. Inclusive plurals and the theory of number. Linguistic Inquiry 51 (1): 37-74.

Martí, Luisa. 2020b. Numerals and the theory of number. Semantics \& Pragmatics. https://doi.org/10. 3765/sp.13.3. 
Massam, Diane. 2001. Pseudo noun incorporation in Niuean. Natural Language \& Linguistic Theory 19 (1): $153-197$.

Mayr, Clemens. 2015. Plural definite NPs presuppose multiplicity via embedded exhaustification. In Proceedings of semantics and linguistic theory (SALT) 25, ed. Sarah D'Antonio, Mary Moroney, and Carol Rose Little, 204-224. Washington, DC: LSA.

Noveck, Ira. 2001. When children are more logical than adults: Experimental investigations of scalar implicatures. Cognition 78 (8): 165-188.

Öztürk, Balkız. 2005. Case, referentiality, and phrase structure. Amsterdam: John Benjamins.

Papafragou, Anna, and Julien Musolino. 2003. Scalar implicatures: Experiments at the semanticspragmatics interface. Cognition 86 (3): 253-282.

Renans, Agata, Jacopo Romoli, Maria-Margarita Makri, Lyn Tieu, Hanna de Vries, Raffaella Folli, and George Tsoulas. 2018. The abundance inference of pluralised mass nouns is an implicature: Evidence from Greek. Glossa: A Journal of General Linguistics 1 (3): 1-34.

Sağ, Yağmur. 2018. The semantics of numeral constructions in Turkish. In Proceedings of Sinn und Bedeutung (SuB) 22, ed. Uli Sauerland and Stephanie Solt, 307-324. Berlin: Leibniz Centre General Linguistics.

Sağ, Yağmur. 2019. The semantics of number marking: Reference to kinds, counting, and optional classifiers. PhD dissertation, Rutgers University.

Sauerland, Uli. 2003. A new semantics for number. In Proceedings of semantics and linguistic theory (SALT) 13, ed. Robert B. Young and Yuping Zhou, 258-275. Ithaca, NY: CLC Publications.

Sauerland, Uli, Jan Andersen, and Kazuko Yatsushiro. 2005. The plural is semantically unmarked. In Linguistic evidence: Empirical, theoretical, and computational perspectives, ed. Stephan Kepser and Marga Reis, 413-434. Berlin: Mouton de Gruyter.

Schwarzschild, Roger. 1996. Pluralities. Dordrecht: Kluwer.

Scontras, Greg. 2014. The semantics of measurement. PhD dissertation, Harvard University.

Sigler, Michele. 1996. Specificity and Agreement in Standard Western Armenian. PhD Dissertation, Massachusetts Institute of Technology.

Sebüktekin, I.Hikmet. 1971. Turkish-English contrastive analysis. Turkish morphology and corresponding English structures. The Hague: Mouton.

Spector, Benjamin. 2007. Aspects of the pragmatics of plural morphology: On higher-order implicatures. In Presupposition and implicature in compositional semantics, ed. Uli Sauerland and Penka Stateva, 243-281. Basingstoke: Palgrave Macmillan.

Tieu, Lyn, and Jacopo Romoli. 2019. Plurality. In Handbook of experimental semantics and pragmatics, ed. Chris Cummins and Napoleon Katsos, 208-227. Oxford: Oxford University Press.

Tieu, Lyn, Manuel Križ, and Emmanuel Chemla. 2019a. Children's acquisition of homogeneity in plural definite descriptions. Frontiers in Psychology, Nov. 6 (2019): 2329. https://doi.org/10.3389/fpsyg. 2019.02329.

Tieu, Lyn, Cory Bill, and Jacopo Romoli. 2019b. Homogeneity or implicature: An experimental investigation of free choice. In Proceedings of Semantics and Linguistic Theory (SALT) 29, ed. Katherine Blake and Forrest Davis, 706-726. https://doi.org/10.3765/salt.v29i0.4631.

Tieu, Lyn, Cory Bill, Jacopo Romoli, and Stephen Crain. 2020. Testing theories of plural meanings. Cognition (to appear). https://doi.org/10.1016j.cognition.2020.104307.

van Tiel, Bob, Emiel van Miltenburg, Natalia Zevakhina, and Bart Geurts. 2014. Scalar diversity. Journal of Semantics 33 (1): 137-175.

Wankoff, Lorain Szabo, and Helen S. Cairns. 2009. Why ambiguity detection is a predictor of early reading skill. Communication Disorders Quarterly 30 (3): 183-192.

Zweig, Eytan. 2009. Number-neutral bare plural and the multiplicity implicature. Linguistics and Philosophy 32: 353-407.

Publisher's Note Springer Nature remains neutral with regard to jurisdictional claims in published maps and institutional affiliations. 